\title{
Visfatin as a predictor of obstructive sleep apnea in atrial fibrillation patients
}

\author{
Anna Szymanska ${ }^{1} \cdot$ Anna E. Platek $^{2}$ - Janusz Sierdzinski ${ }^{3} \cdot$ Filip M. Szymanski ${ }^{4}$
}

Received: 5 November 2019 /Revised: 24 January 2020 / Accepted: 28 January 2020 / Published online: 13 March 2020

(C) The Author(s) 2020

\begin{abstract}
Background Obstructive sleep apnea (OSA) often coexists with atrial fibrillation (AF) and makes the course of AF worse. The negative impact of OSA on AF may be due to atrial stretch, hypoxia, hypertension, obesity, fibrosis, and inflammation. Several mediators are thought to be responsible for this correlation, among them adipokines such as visfatin. This study aimed to assess the association between visfatin concentrations and OSA in patients with AF.

Aims This study aimed to assess the association between visfatin concentrations and OSA in AF patients.

Methods In a tertiary Cardiology Department, hospitalized patients previously diagnosed with AF were enrolled in the study. Diagnosis of OSA was made based on a respiratory polygraphy and patients had blood samples taken for assessment of plasma visfatin concentration.

Results A total of 266 patients with AF (65\% men, age $57.6 \pm 10.1)$ were enrolled, and $121(45 \%)$ were diagnosed with OSA. Patients with OSA had higher visfatin concentrations than those without OSA $(2.13 \pm 0.17$ vs. $1.70 \pm 0.21 \mathrm{ng} / \mathrm{mL} ; p=0.04)$. Patients with mild OSA had visfatin levels equal to $1.77 \pm 0.17 \mathrm{ng} / \mathrm{mL}$, moderate OSA $2.38 \pm 0.18 \mathrm{ng} / \mathrm{mL}$, and severe OSA $3.55 \pm 0.61 \mathrm{ng} / \mathrm{mL}$ ( $p$ for trend $=0.017$ ). Multivariate regression analysis showed that increased visfatin concentrations were associated with the risk of OSA (odds ratio 1.92; 95\% confidence interval 1.09-3.40).

Conclusions Patients with AF who were diagnosed with OSA had significantly higher plasma visfatin levels which increased according to the severity of OSA. Furthermore, multivariate regression analysis identified visfatin concentration over $1.25 \mathrm{ng} /$ $\mathrm{mL}$, male sex, age over 59.1 years, and permanent $\mathrm{AF}$ as the factors showing independent correlation with OSA.
\end{abstract}

Keywords Obstructive sleep apnea $\cdot$ Biomarkers $\cdot$ Visfatin $\cdot$ Arrhythmia $\cdot$ Sleep disordered breathing

\section{Introduction}

Atrial fibrillation (AF) has a highly negative impact on the patient's prognosis due to its association with an elevated risk of thromboembolic events and stroke [1,2]. Obstructive sleep

Anna Szymanska

anna.szymanska@cmkp.edu.pl

1 Department of Heart Diseases, Medial Centre of Postgraduate Education, Warsaw, Poland

2 Department of General and Experimental Pathology, Centre for Preclinical Research and Technology, Medical University of Warsaw, Warsaw, Poland

3 Department of Medical Informatics and Telemedicine, Medical University of Warsaw, Warsaw, Poland

4 Department of Cardiology, Medical University of Warsaw, Warsaw, Poland apnea (OSA) is one of the conditions that contribute negatively to the AF course. OSA affects at least $2 \%$ to $4 \%$ of the adult population and the prevalence rates increased over the last 2 decades [3]. OSA is associated with prolonged intermittent hypoxia. It is increasingly recognized and also a major risk factor for cardiovascular disease, including AF. The negative impact of OSA on AF may be due to atrial stretch, hypoxia, hypertension, obesity, fibrosis, or inflammation.

Several mediators are thought to be responsible for this correlation, among them adipokines such as visfatin. Visfatin is also known as nicotinamide phosphoribosyltransferases (NAMPT) and is identical to the pre-B cell colony-enhancing factor (PBEF) [4]. It is synthesized mainly in the visceral fat tissue. Visfatin has an important prognostic utility in patients with cardiovascular disease due to its strong correlation with inflammation, obesity, remodeling, and carcinogenesis. Recent research on visfatin shows also its strong correlation with hypoxia [5]. Various biomarkers are currently being tested as simple and accessible determinants of OSA. 
The aim of the study was to assess the association between visfatin concentrations and OSA in AF patients.

\section{Material and methods}

The study was an observational study including consecutive patients hospitalized in a Cardiology Department with a primary diagnosis of AF. The regional Ethics Committee approved the study design and protocol, and an informed consent was provided by every participant during the study enrolment. The study included patients aged $\geq 18$ years with a confirmed diagnosis of non-valvular AF who were prequalified for heart rhythm control strategy. The study exclusion criteria were overnight respiratory study. Additional comorbidities and cardiovascular risk factors have been diagnosed based on medical history or de novo diagnosis during the current hospitalization. The methodology has been described in detail previously [6]. The diagnosis of AF and its classification into paroxysmal, permanent, or persistent was made base on the current medical practice standards.

In addition to the routine screening and examination, all patients had their blood taken for assessment of visfatin concentration and had an overnight respiratory polygraphy study performed. The study was performed using Embletta MPR devices (Flaga, Reykjavik, Iceland) that are eligible for objective OSA diagnosis confirmation. Scoring of the studies was made manually by a certified sleep medicine specialist, following the American Academy of Sleep Medicine guidelines [7].

Blood samples for biochemical assessment were collected after overnight fasting. Samples were centrifuged for $10 \mathrm{~min}$ at $1000 \times \mathrm{g}$ for serum and then stored at $-20^{\circ} \mathrm{C}$ for assay. Serum visfatin levels were measured with the commercially available sandwich enzyme-linked immunosorbent assay (ELISA, (Cat\# K4907-100, BioVision, Milpitas, CA, USA). The method included binding visfatin with absorbed monoclonal antibody to human visfatin. All samples were assessed at the same time in a single certified laboratory. Measuring range was 0.125 to $8 \mathrm{ng} /$ $\mathrm{mL}$, and assay sensitivity was $0.030 \mathrm{ng} / \mathrm{mL}$. All samples were assayed in duplicate, and mean concentration from the 2 assays was included in the analysis. On each analysis plate, a calibration curve was made to assure the proper reading of the assays. The test was done with intra-assay coefficients of variability below $2 \%$. The methodology of biochemical assessment has been described in detail previously [8].

All statistical analyses were performed using SPSS (SPSS version 21, Inc., Chicago, IL) for macOS. Obtained data were tested for normality using the Kolmogorov-Smirnov test. Data showing continuous distribution are presented as mean and $95 \%$ confidence intervals (CI), and their comparison was made using the Mann-Whitney test or Student's $t$ test. The categorical variables were compared using the chi-squared or Fisher exact tests. Forward stepwise multivariate logistic regression models were created to identify the independent predictors of OSA. The predictive value of the visfatin concentration was tested by the area under the receiver operator characteristic (ROC) curve.

\section{Results}

Two hundred sixty-six patients were included (65\% male, aged $57.6 \pm 10.1$ years). Arterial hypertension was diagnosed in $72.9 \%$ of patients, $8.3 \%$ had diabetes, and $10.9 \%$ were diagnosed with vascular disease. Paroxysmal AF was observed in $185(69.5 \%)$ patients (Table 1). All patients were also assessed in guideline-recommended risk scores.

The respiratory polygraphy revealed OSA in $121(45.49 \%)$ patients. OSA patients were significantly older ( $59.6 \pm 8$ vs. $56 \pm$ 11.4 years; $p=0.02$ ) with higher body mass index (30.9 \pm 5.4 vs. $28.7 \pm 4.4 \mathrm{~kg} / \mathrm{m} 2 ; p<0.01)$ than non-OSA ones. Patients with OSA more often had arterial hypertension (77.7\% vs. $69.0 \%$; $p=0.03$ ), history of stroke or peripheral thromboembolism $(12.4 \%$ vs. $5.5 \% ; p=0.03)$, and vascular disease $(14.9 \%$ vs. $7.6 \% ; p=0.045)$ compared to those without the disease.

When we analyzed visfatin concentrations, it showed that OSA patients had higher visfatin concentrations than those without OSA $(2.13 \pm 0.17$ vs. $1.70 \pm 0.21 \mathrm{ng} / \mathrm{mL} ; p=0.04)$. Mild OSA patients had visfatin levels equal to $1.77 \pm 0.17 \mathrm{ng} / \mathrm{mL}$, moderate OSA $2.38 \pm 0.18 \mathrm{ng} / \mathrm{mL}$, and severe OSA $3.55 \pm$ $0.61 \mathrm{ng} / \mathrm{mL}$ ( $p$ for trend $=0.017$ ) (Figure 1). Several other parameters were also positively associated with OSA severity (Table 2).

Multivariate regression analysis showed that increased visfatin concentrations were associated with the risk of obstructive sleep apnea (odds ratio 1.92; 95\% confidence interval 1.093.40). Other factors correlating with OSA risk are shown in Table 3. The area under the ROC curve for the visfatin to predict any type of OSA was 0.60 ; for predicting moderate to severe OSA, it was 0.74 and for severe OSA 0.89 .

Table 1 Baseline characteristics of the study population

\begin{tabular}{ll}
\hline Parameter & $\begin{array}{l}\text { Value } \pm \text { standard } \\
\text { deviation or } n(\%)\end{array}$ \\
\hline Age (years) & $57.6 \pm 10.1$ \\
Systolic blood pressure $(\mathrm{mmHg})$ & $131.7 \pm 16.7$ \\
Diastolic blood pressure $(\mathrm{mmHg})$ & $80.7 \pm 11.1$ \\
Body mass index $\left(\mathrm{kg} / \mathrm{m}^{2}\right)$ & $29.7 \pm 5$ \\
AHI $\left(\mathrm{h}^{-1}\right)$ & $8.1 \pm 10.7$ \\
Visfatin $(\mathrm{ng} / \mathrm{ml})$ & $1.9 \pm 2.1$ \\
Male sex & $173(65 \%)$ \\
Heart failure & $3(1.1 \%)$ \\
Arterial hypertension & $194(72.9 \%)$ \\
Diabetes mellitus & $22(8.3 \%)$ \\
Stroke or peripheral thromboembolism & $23(8.6 \%)$ \\
Vascular disease & $29(10.9 \%)$ \\
Paroxysmal atrial fibrillation & $185(69.5 \%)$ \\
\hline
\end{tabular}




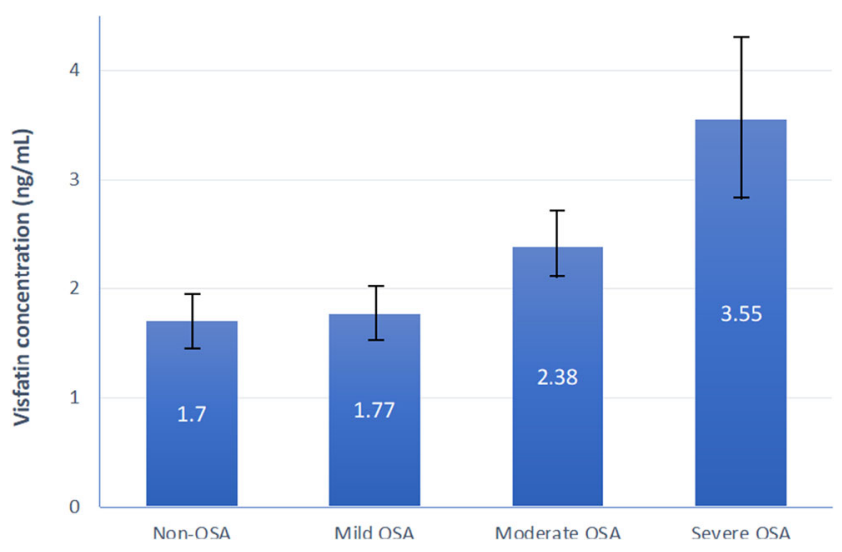

Fig. 1 The concentration of visfatin according to the sleep apnea severity

\section{Discussion}

The present study revealed that plasma visfatin concentration (over $1.25 \mathrm{ng} / \mathrm{mL}$ ) is one of the indicators of OSA. Other factors associated with an elevated risk of OSA are male sex, permanent atrial fibrillation, and age. Moreover, visfatin concentration positively correlates with OSA severity.

Those findings are especially important in AF patients due to the strong association between OSA and AF outcomes. OSA increases the arrhythmia symptoms and progression, worsens the rhythm control strategy outcomes, and is a predictor of increased thromboembolic and cardiovascular risk [9]. Therefore, early diagnosis and treatment of OSA improve patient's prognosis in terms of cardiovascular health, as well as, for example, outcomes of sinus rhythm restoration procedures.

The underlying mechanisms linking the elevated visfatin concentrations with an increased risk of OSA could be explained by an OSA-caused repeated intermittent hypoxia. Hypoxia causes several changes at both cellular and molecular levels [10]. Hypoxia was shown to be associated with activation of certain genes, including those responsible for the changes in metabolism as well as inflammatory process [11, 12]. Moreover, transient episodes of hypoxia contribute to the
Table 3 Factors associated with an elevated risk of obstructive sleep apnea

Odds ratio estimates

\begin{tabular}{llll}
\hline Effect & Point estimate & \multicolumn{2}{l}{$\begin{array}{l}95 \% \text { Wald } \\
\text { confidence limits }\end{array}$} \\
\hline Elevated visfatin level $^{*}$ & 1.916 & 1.079 & 3.399 \\
Male sex & 2.092 & 1.147 & 3.816 \\
Older age $^{* *}$ & 1.062 & 1.029 & 1.095 \\
Permanent atrial fibrillation & 1.914 & 1.056 & 3.470 \\
\hline
\end{tabular}

*Visfatin concentration over $1.25 \mathrm{ng} / \mathrm{mL}$

**Age over 59.1 years

development of an increased blood pressure; sympathetic stimulation; increased production of reactive oxygen species; and depletion in the functioning of cardiomyocytes, conductive system, and endothelium [13]. These changes may be responsible for complex remodeling that occurs in OSA patients, especially regarding the cardiac conductive system. It potentially results in arrhythmias such as AF.

Correlation of visfatin with OSA-related hypoxia is probably mediated via HIF1. Studies suggest that visfatin mRNA expression is upregulated in the fat tissue of obesity through the activation of HIF1-alpha pathway due to hypoxia [5]. Moreover, severity and time from the onset of hypoxia (also associated with OSA) correlate with visfatin levels [12]. Therefore, this biomarker may have potential in OSA screening and assessment of OSA-related hypoxemic tissue damage.

The main limitation in the first part of the study was an ambulatory recording used for the sleep evaluation. This type of recordings does not include electroencephalography recording. Because of it, several limitations arise. Hypopneas associated only with arousals are not detected and not included in the data. Sleep time is only approximated and not based on EEG recording. All of this can affect the obtained AHI score [14]. Nevertheless, outpatient RP is widely used and

Table 2 Comparison of patients according to the sleep apnea severity

\begin{tabular}{|c|c|c|c|c|c|}
\hline Parameter & $\begin{array}{l}\text { Patients without obstructive } \\
\text { sleep apnea }(n=145)\end{array}$ & $\begin{array}{l}\text { Mild sleep } \\
\text { apnea }(n=74)\end{array}$ & $\begin{array}{l}\text { Moderate sleep } \\
\text { apnea }(n=35)\end{array}$ & Severe sleep apnea $(n=12)$ & $p$ for trend \\
\hline Age (years) & $55.9 \pm 11.4$ & $59.6 \pm 8.5$ & $59.9 \pm 7.2$ & $58.6 \pm 6.9$ & 0.12 \\
\hline Systolic blood pressure (mmHg) & $130.9 \pm 16.7$ & $133.2 \pm 16.6$ & $132.1 \pm 18.3$ & $131.7 \pm 15.1$ & 0.88 \\
\hline Diastolic blood pressure (mmHg) & $79.7 \pm 10.7$ & $82.8 \pm 10.7$ & $80.9 \pm 12.9$ & $79.6 \pm 12.1$ & 0.31 \\
\hline Body mass index $\left(\mathrm{kg} / \mathrm{m}^{2}\right)$ & $28.7 \pm 4.4$ & $30.1 \pm 5.5$ & $31.3 \pm 4.6$ & $34.4 \pm 6.3$ & 0.001 \\
\hline Male sex & $88(60.7 \%)$ & $55(74.3 \%)$ & $24(68.6 \%)$ & $6(50.0 \%)$ & 0.56 \\
\hline Heart failure & $1(0.7 \%)$ & $0(0.0 \%)$ & $0(0.0 \%)$ & $2(16.7 \%)$ & 0.008 \\
\hline Arterial hypertension & $100(69.0 \%)$ & $55(74.3 \%)$ & $32(91.4 \%)$ & $10(83.3 \%)$ & 0.012 \\
\hline Diabetes mellitus & $11(7.6 \%)$ & $4(5.4 \%)$ & $7(20.0 \%)$ & $5(41.7 \%)$ & 0.001 \\
\hline Stroke or peripheral thromboembolism & $8(5.5 \%)$ & $9(12.2 \%)$ & $4(11.4 \%)$ & $2(16.7 \%)$ & 0.029 \\
\hline Vascular disease & $11(7.6 \%)$ & $7(9.5 \%)$ & $8(22.9 \%)$ & $3(25.0 \%)$ & 0.005 \\
\hline
\end{tabular}


accepted as an alternative for polysomnography, and some major studies are based on this tool [15]. Another limitation of the study is the fact that the visfatin concentration was assessed only once and not reassessed in those scheduled a continuous positive pressure therapy treatment.

In conclusion, the presence of OSA and its severity in $\mathrm{AF}$ patients is associated with higher visfatin levels. The multivariate regression analysis identified visfatin concentration over $1.25 \mathrm{ng} / \mathrm{mL}$ and such factors as male sex, age over 59.1 years, and permanent atrial fibrillation as a risk factor for OSA. The utility of visfatin assessment for OSA screening requires further studies.

Funding information This is a self-funded study, and it has not received and founding.

\section{Compliance with ethical standards}

Conflict of interest Filip M. Szymanski has received consulting fees/ honoraria from Boehringer Ingelheim, for subjects not directly related to the topic of the current study. Except for that, all other authors certify that they have no affiliations with or involvement in any organization or entity with any financial interest (such as honoraria; educational grants; participation in speakers' bureau, membership, employment, consultancies, stock ownership, or other equity interest; and expert testimony or patent-licensing arrangements) or nonfinancial interest (such as personal or professional relationships, affiliations, knowledge, or beliefs) in the subject matter or materials discussed in this manuscript.

Ethical approval All procedures performed in studies involving human participants were following the ethical standards of the institutional and/ or national research committee and with the 1964 Helsinki declaration and its later amendments or comparable ethical standards.

Informed consent All individual patients included into that study gave an informed consent for participation.

Open Access This article is licensed under a Creative Commons Attribution 4.0 International License, which permits use, sharing, adaptation, distribution and reproduction in any medium or format, as long as you give appropriate credit to the original author(s) and the source, provide a link to the Creative Commons licence, and indicate if changes were made. The images or other third party material in this article are included in the article's Creative Commons licence, unless indicated otherwise in a credit line to the material. If material is not included in the article's Creative Commons licence and your intended use is not permitted by statutory regulation or exceeds the permitted use, you will need to obtain permission directly from the copyright holder. To view a copy of this licence, visit http://creativecommons.org/licenses/by/4.0/.

\section{References}

1. Go AS, Hylek EM, Phillips KA, Chang Y, Henault LE, Selby JV, Singer DE (2001) Prevalence of diagnosed atrial fibrillation in adults: national implications for rhythm management and stroke prevention: the AnTicoagulation and Risk Factors in Atrial Fibrillation (ATRIA) Study. JAMA 285:2370-2375. https://doi. org/10.1001/jama.285.18.2370
2. Kamel H, Okin PM, Elkind MS, Iadecola C (2016) Atrial fibrillation and mechanisms of stroke: time for a new model. Stroke 47: 895-900. https://doi.org/10.1161/STROKEAHA.115.012004

3. Peppard PE, Young T, Barnet JH, Palta M, Hagen EW, Hla KM (2013) Increased prevalence of sleep-disordered breathing in adults. Am J Epidemiol 177:1006-1014. https://doi.org/10.1093/aje/kws342

4. Carbone F, Liberale L, Bonaventura A, Vecchiè A, Casula M, Cea M, Monacelli F, Caffa I, Bruzzone S, Montecucco F, Nencioni A (2017) Regulation and function of extracellular nicotinamide phosphoribosyltransferase/Visfatin. Compr Physiol 7:603-621. https://doi.org/10.1002/cphy.c160029

5. Segawa K, Fukuhara A, Hosogai N, Morita K, Okuno Y, Tanaka M, Nakagawa Y, Kihara S, Funahashi T, Komuro R, Matsuda M, Shimomura I (2006) Visfatin in adipocytes is upregulated by hypoxia through HIF1alpha-dependent mechanism. Biochem Biophys Res Commun 349:875-882. https://doi.org/10.1016/j.bbrc.2006.07.0

6. Szymanski FM, Filipiak KJ, Platek AE, Hrynkiewicz-Szymanska A, Kotkowski M, Kozluk E, Kiliszek M, Sierdzinski J, Opolski G (2015) Presence and severity of obstructive sleep apnea and remote outcomes of atrial fibrillation ablations - a long-term prospective, cross-sectional cohort study. Sleep Breath 19:849-856. https://doi. org $/ 10.1007 / \mathrm{s} 11325-014-1102-\mathrm{x}$

7. Berry RB, Brooks R, Gamaldo CE et al for the American Academy of Sleep Medicine(2016) The AASM manual for the scoring of sleep and associated events: rules. Specifications, Terminology and Technical

8. Platek AE, Szymanska A, Kalaszczynska I, Szymanski FM, Sierdzinski J, Filipiak KJ (2020) Usefulness of visfatin as a predictor of atrial fibrillation recurrence after ablation procedure. Am J Cardiol 125:415-419. https://doi.org/10.1016/j.amjcard.2019.10.052

9. Szymanski FM, Filipiak KJ, Platek AE, Hrynkiewicz-Szymanska A, Karpinski G, Opolski G (2015) Assessment of CHADS2 and CHA2DS2-VASc scores in obstructive sleep apnea patients with atrial fibrillation. Sleep Breath 19:531-537. https://doi.org/10. 1007/s11325-014-1042-5

10. Ben-Shoshan J, Maysel-Auslender S, Mor A, Keren G, George J (2008) Hypoxia controls CD4+CD25+ regulatory T-cell homeostasis via hypoxia-inducible factor-1a. Eur J Immunol 38:2412-2418. https://doi.org/10.1002/eji.2008383

11. Eltzschig Holger K, Carmeliet $P$ (2011) Hypoxia and inflammation. N Engl J Med 364:656-665. https://doi.org/10.1056/ NEJMra0910283

12. Semenza G, Prabhakar N (2015) Neural regulation of hypoxiainducible factors and redox state drives the pathogenesis of hypertension in a rodent model of sleep apnea. J Appl Physiol 119:11521156. https://doi.org/10.1152/japplphysiol.00162.201

13. Rausch LK, Hofer M, Pramsohler S, Kaser S, Ebenbichler C, Haacke S, Gatterer H, Netzer NC (2018) Adiponectin, leptin and visfatin in hypoxia and its effect for weight loss in obesity. Front Endocrinol 9:615. https://doi.org/10.3389/fendo.2018.00615

14. Redline S, Kapur VK, Sanders MH, Quan SF, Gottlieb DJ, Rapoport DM, Bonekat WH, Smith PL, Kiley JP, Iber C (2000) Effects of varying approaches for identifying respiratory disturbances on sleep apnea assessment. Am J Respir Crit Care Med 161:369-374. https://doi.org/10.1164/ajrccm.161.2.9904031

15. Collop NA, Anderson WM, Boehlecke B, Claman D, Goldberg R, Gottlieb DJ, Hudgel D, Sateia M, Schwab R, Portable Monitoring Task Force of the American Academy of Sleep Medicine (2007) Clinical guidelines for the use of unattended portable monitors in the diagnosis of obstructive sleep apnea in adult patients. J Clin Sleep Med 3:737-747

Publisher's note Springer Nature remains neutral with regard to jurisdictional claims in published maps and institutional affiliations. 